\title{
Micro- and Nanostructures of Agave Fructans to Stabilize Compounds of High Biological Value via Electrohydrodynamic Processing
}

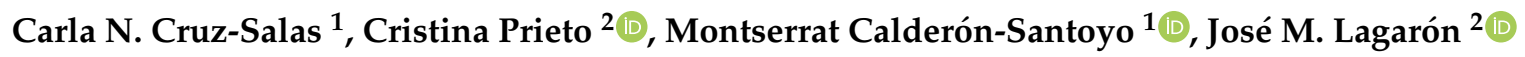 \\ and Juan A. Ragazzo-Sánchez $1, *(\mathbb{0}$ \\ 1 Laboratorio Integral de Investigación en Alimentos, Tecnológico Nacional de México/Instituto Tecnológico \\ de Tepic, Av. Tecnológico 2595, Tepic C.P. 63175, Nayarit, Mexico; ccruz@ittepic.edu.mx (C.N.C.-S.); \\ montserratcalder@gmail.com (M.C.-S.) \\ 2 Novel Materials and Nanotechnology Group, IATA-CSIC, Calle Catedrático Agustín Escardino Benlloch 7, \\ 46980 Paterna, Spain; cprieto@iata.csic.es (C.P.); lagaron@iata.csic.es (J.M.L.) \\ * Correspondence: arturoragazzo@hotmail.com or jragazzo@ittepic.edu.mx; Tel.: +52-311-2119400 (ext. 233)
}

Received: 24 October 2019; Accepted: 12 November 2019; Published: 21 November 2019

\begin{abstract}
This study focuses on the use of high degree of polymerization agave fructans (HDPAF) as a polymer matrix to encapsulate compounds of high biological value within micro- and nanostructures by electrohydrodynamic processing. In this work, $\beta$-carotene was selected as a model compound, due to its high sensitivity to temperature, light and oxygen. Ultrafine fibers from HDPAF were obtained via this technology. These fibers showed an increase in fiber diameter when containing $\beta$-carotene, an encapsulation efficiency (EE) of $95 \%$ and a loading efficiency (LE) of $85 \%$. The thermogravimetric analysis (TGA) showed a $90{ }^{\circ} \mathrm{C}$ shift in the $\beta$-carotene decomposition temperature with respect to its independent analysis, evidencing the HDPAF thermoprotective effect. Concerning the HDPAF photoprotector effect, only $21 \%$ of encapsulated $\beta$-carotene was lost after $48 \mathrm{~h}$, while non-encapsulated $\beta$-carotene oxidized completely after $24 \mathrm{~h}$. Consequently, fructans could be a feasible alternative to replace synthetic polymers in the encapsulation of compounds of high biological value.
\end{abstract}

Keywords: HDPAF; electrospinning; micro-nanofibers; $\beta$-carotene; thermoprotection; photoprotection

\section{Introduction}

Obtaining micro- and nanostructures in the food industry represents a viable option for the incorporation and stabilization of compounds of high biological value (CHBV). The production of these structures containing CHBV is based on the encapsulation processes in which the bioactive is surrounded by polymeric materials that act as matrices and help to preserve their properties. Currently, there is a huge interest in the use of biopolymers that replace synthetic polymers in the encapsulation and transport processes of compounds of high biological value, as well as expanding their use in biomedical and pharmaceutical technologies [1,2]. Fructans are a new class of heterodispersed biopolymers that are found in various plants, such as the Agave tequilana from the Agavaceae family, and serve as an important source of reserve carbohydrates in the plant. Five types of fructans have been identified in nature so far, which are classified into inulins, neo-inulins, levans, neo-levans and mixed fructans, depending on the type of bond [3,4]. Agave fructans are characterized by the presence of fructose units with a terminal glucose connected by bonds $\beta(2-1)$ and $\beta(2-6)$ and can present different degrees of polymerization, which are determined by the species [5-7] as well as the environmental conditions in which the agave is produced, stored and processed $[8,9]$. 
Toriz et al. (2007) [10] propose a chemical structure for the fructans of Agave tequilana Weber var. Azul, based on the combination of permethylation and reductive rupture techniques for identification. They mainly propose the distribution of two monomers, the $\beta$-D fructofuranose terminal type $(22 \%)$, 1-linked (30.8\%), 6-linked (21.2\%), 1-6 linked (19.8\%) and the $\alpha$-D terminal glucopiranose (7.3\%).

The use of high degree of polymerization agave fructans (HDPAF) has been implemented in recent years as a wall material in encapsulation processes such as spray drying, obtaining remarkable results. Ortiz-Basurto et al. (2017) [11] microencapsulated pitanga juice (Eugenia uniflora L.) by spray drying with HDPAF and maltodextrin as encapsulants. These authors reported similar behaviors between both materials. Alternatively, Farías Cervantes et al. (2016) [12] used 50\% agave fructans, as an encapsulant to obtain blackberry powder by spray drying, mentioning that agave fructans, in addition to increasing the encapsulation efficiency, could add prebiotic properties and improve the physico-chemical characteristics of the powder.

However, conventional encapsulation processes, such as spray drying, require the use of high temperatures or toxic reactives that could affect the CHBV or compromise its application in a food or pharmaceutical product. The electrohydrodynamic processing, electrospinning or electrospraying, has demonstrated to be a promising alternative to encapsulate and stabilize compounds of high biological value, since it does not require severe conditions of temperature, pressure or aggressive chemicals [13]. This technology allows obtaining structures called fibers or particles at the micron, submicron or nano scale [14]. This technique uses a potential difference for the electro-stretching of a drop of polymer solution from a charged electrode (capillary or free surface) to a collector. Once the drop has gained enough electrical charge to overcome the surface tension and viscosity of the polymer, the drop is stretched, causing ultra-fine fibers to emerge from the polymer drop, forming the so-called Taylor cone [15]. The extent of each phase, whether direct or in drag motion, depends on the operating parameters as well as the physical properties of the polymer, such as surface tension, conductivity and viscosity [16]. The difference between electrospinning and electrospraying (electrohydrodynamic spraying) is based on the degree of molecular cohesion, which can be easily controlled by variation in the concentration of the polymer solution [17]. Ramos-Hernández et al. (2018) [18] managed to obtain spherical structures with a size distribution of 440 to $880 \mathrm{~nm}$, as well as the thermostability and photostability of $\beta$-carotene encapsulated by electrospraying, using solutions with concentrations from $10 \%$ to $50 \%$ of HDPAF.

Electro-spun nanofibers have also been used in CHBV encapsulation processes, such as the encapsulation of bioactive compounds in zein fibers with application in food and pharmaceutical products [19]; however, up to our knowledge, the production of electro-spun micro-nanofibers of HDPAF has not been reported yet. This material could be a feasible alternative to replace synthetic polymers in the encapsulation of compounds of high biological value, as well as expanding their use in biomedical and pharmaceutical products.

Antioxidants are a good example of CHBV due to the high number of health benefits attributed to them and their high sensitivity to physico-chemical factors [20]. Carotenoids are an important member of the antioxidant family, being natural organic pigments present in plants and some photosynthetic organisms. Their consumption is associated with health benefits by reducing the incidence of cancer and heart disease, as well as improving ocular health [21]. $\beta$-carotene is one of the most common carotenoids in the functionality of food, supplements and pharmaceuticals due to its high, pro-vitamin A activity and antioxidant capacity. However, its use is sometimes limited due to its sensitivity to oxidation, especially when exposed to high temperatures, light, oxygen, acidic conditions, etc. [19,22].

The aim of this study was to evaluate the feasibility of agave fructans to obtain micro-nanofibers through the electrospinning process, using $\beta$-carotene as a model compound, with properties and characteristics, as a first approach, and to provide stability to compounds of high biological value for further applications in the food and pharmaceutical areas. 


\section{Materials and Methods}

\subsection{Materials}

High degree of polymerization agave fructans (HDPAF) were obtained in the Laboratorio Integral de Investigación en Alimentos (LIIA) of Tecnológico Nacional de México/Instituto Tecnológico de Tepic, Nayarit, México, from native fructans provided by the company Campos Azules Co. (Mexico City, Mexico); $\beta$-carotene (>97.0\% UV, C40H56) (Sigma Aldrich, Steinheim, Germany), 96\% ethyl alcohol (CTR Scientific, Monterrey N.L, Mexico), Chloroform (trichloromethane) HPLC grade (Fermon Episolv, Monterrey N.L, Mexico), Tego ${ }^{\circledR}$ SML (Evonik Industries AG, Essen, Germany).

\subsection{Preparation and Characterization of Polymer Solutions}

Polymeric solutions were prepared with $70 \%(w / w)$ of HDPAF in hydroalcoholic solution (ethanol-water, at $10 \% w / w)$ and $1 \%(w / w)$ of Tego ${ }^{\circledR}$ SML as surfactant was added. The solution was homogenized under magnetic stirring for $45 \mathrm{~min}$ at room temperature. In the alcoholic fraction of the solution, $\beta$-carotene was added $(1 \% w / w)$, protecting the mixture from light during the homogenization period with dark paper.

The characterization of the solutions consisted in determining the electrical conductivity, viscosity and surface tension. The electrical conductivity was analyzed with a multiparameter potentiometer Hanna Instruments HI-4521 (Melrose, MA, USA). The viscosity ( $\eta$ ) was determined with a Discovery HR-1 Hybrid rheometer (TA Instruments, New Castle, DE, USA), equipped with geometry Smart Swap ${ }^{\mathrm{TM}}$ with automatic detection. The cone and plate geometry option was selected $\left(2^{\circ}, 60 \mathrm{~mm}\right.$ of diameter, $64 \mu \mathrm{m}$ of gap) and the Peltier system for temperature stabilization was used. The surface tension was measured with the equipment Force tensiometer model K20 EasyDyne (KRÜSS GmbH, Hamburg, Germany), with the Wilhelmy Plate method.

\subsection{Obtaining Fibers by Electrospinning}

The electrospinning process was performed in a machine LE-10 brand Fluidnatek ${ }^{\circledR}$ from BIOINICIA company (Valencia, Spain), which has a voltage power supply of $19 \mathrm{kV}$. The injector is based on a syringe pump with a flow from $200 \mu \mathrm{L} / \mathrm{h}$, and has a distance from the injector to the collector of $20 \mathrm{~cm}$, the collector is cylindrical stainless steel and it has a variable rotation speed from $500 \mathrm{rpm}$. The process parameters such as voltage, flow, distance and rotation speed of the collector were adjusted in preliminary tests according to the characterization and stability of the solutions.

\subsection{Morphology Analysis through SEM}

The morphology and size of the fibers obtained were both determined with the scanning electron microscopy (SEM) technique with a Hitachi-S-4800 device (Hitachi High-Technologies Corporation, Tokyo, Japan). Approximately $1.5 \mathrm{mg}$ of sample was fixed with double-sided tape on the sample holder, coated with gold-palladium for $2 \mathrm{~min}$, and an acceleration voltage of $10 \mathrm{kV}$ was used. The determination of the size distribution based on the diameters of the structures was made with the SEM system software (Hitachi High-Technologies Corporation, Tokyo, Japan) with at least 100 measurements per sample.

\subsection{Loading and Encapsulation Efficiency}

The loading efficiency (LE) of $\beta$-carotene in the fibers was determined considering the amount of total extract and final extract by weight difference, obtained with thermogravimetry analysis (TGA) using the TRIOS software (TA Instruments, New Castle, DE, USA) and applying Equation (1). Where the total extract corresponds to the amount of extract added to the fibers, the final extract represents the amount of extract determined by TGA. Regarding the encapsulation efficiency (EE), initially the amount of extract loaded was determined with the application of Equation (2). 
Subsequently, the amount of surface was calculated, performing a superficial washing of the fibers with a solvent related to $\beta$-carotene and not to the polymer, in order to determine the content of compounds of high biological value (CHBV) on the fiber surface. To this end, $1 \mathrm{mg}$ of fibers was taken and suspended in $1 \mathrm{~mL}$ of trichloromethane, centrifuging at 10,000 rpm for $1 \mathrm{~min}$, analyzing the supernatant obtained absorbance at $466 \mathrm{~nm}$ in a Varian brand Cary ${ }^{\circledR} 50 \mathrm{UV}$-Vis spectrophotometer (Sydney, Australia). The $\beta$-carotene content is calculated according to the calibration curve performed, $y=3.6298 x+0.0059\left(R^{2}=0.9998\right)$. Finally, knowing the values of loading and surface extract, Equation (3) was applied to determine the encapsulation efficiency (EE).

Loading efficiency (LE)

$$
\% L E=\left(1-\left(\frac{\text { total extract }- \text { final extract }}{\text { total extract }}\right)\right) \times 100
$$

Loading extract

$$
\text { Loading extract }=\frac{\% E C * \text { total extract }}{100}
$$

Encapsulation efficiency (EE)

$$
\% E E=\frac{\text { loading extract }- \text { surface extract }}{\text { loading }} \times 100
$$

\subsection{Thermogravimetric Analysis (TGA)}

The thermogravimetric analysis to determine the decomposition temperature of each component of the fiber, as well as to determine the LE and to demonstrate the thermoprotective effect of the materials on $\beta$-carotene, was performed on a TGA 550 (TA Instruments, New Castle, DE, USA) in a nitrogen atmosphere $\left(\mathrm{N}_{2}\right)$, with a heating ramp of 25 to $600{ }^{\circ} \mathrm{C}$ at a speed of $5{ }^{\circ} \mathrm{C} / \mathrm{min}$. The results were analyzed with the TRIOS software (TA Instruments, New Castle, DE, USA).

\subsection{UV Photostability}

In order to analyze the oxidation kinetics of $\beta$-carotene, the fibers obtained were exposed to a simulator of sunlight. An Osram Ultra-vitalux lamp (300 W) (OSRAM, Munich, Germany) was utilized, which generates a mixture of radiation, using a quartz discharge tube and a tungsten filament [19]. It was placed in a sample holder $1 \mathrm{mg}$ of standard $\beta$-carotene, and samples of the fibers with and without $\beta$-carotene, which were exposed to ultraviolet (UV) radiation for $48 \mathrm{~h}$ at $37^{\circ} \mathrm{C}$. Samples were taken every $6 \mathrm{~h}$. A central segment of the exposed material was cut and dissolved in distilled water at a ratio of $1 \mathrm{mg} / \mathrm{mL}$ with magnetic stirring for $1 \mathrm{~min}$. Subsequently, $1 \mathrm{~mL}$ of chloroform was added and centrifuged (10,000 rpm, $1 \mathrm{~min})$. The absorbance of the organic phase at $466 \mathrm{~nm}$ was measured with the Varian brand Cary ${ }^{\circledR} 50$ UV-Vis spectrophotometer (Sydney, Australia). Chloroform was used as the target. The results, obtained in relation to oxidation, are reported based on the relative content of $\beta$-carotene (\% absorbance).

\subsection{Statistic Analysis}

Data analysis was performed using the least significant digit (LSD) test for comparison of means with STATISTICA version 10 (StatSoft, Inc. (2011), (Tulsa, OK, USA)). All tests were performed in triplicate.

\section{Results and Discussion}

\subsection{Physicochemical Characterization of Polymer Solutions}

First, the physicochemical properties of the polymer solutions were evaluated, since the stability of the electrohydrodynamic process and the morphology obtained are highly related to them. 
The solutions presented viscosity values of $3.69 \pm 0.05$ and $3.36 \pm 0.03 \mathrm{~Pa} \cdot \mathrm{s}$ without and with $\beta$-carotene, respectively, as shown is Table 1 . These results are in the same order of magnitude as those obtained by Kutzli et al. (2019) [23], at high concentrations of maltodextrin combined with whey protein isolated (WPI) or soy protein isolated (SPI). They obtained values of apparent viscosity of $4.85 \pm 0.14 \mathrm{~Pa} \cdot \mathrm{s}$ (WPI 80:5), $5.88 \pm 0.18 \mathrm{~Pa} \cdot \mathrm{s}$ (WPI 80:10), $5.14 \pm 0.09 \mathrm{~Pa} \cdot \mathrm{s}$ (SPI 80:5) and $7.77 \pm 0.12 \mathrm{~Pa} \cdot \mathrm{s}$ (SPI 80:10), respectively. The similarity of fructans with maltodextrin with respect to this property is mainly due to their structural conformation. Concerning the surface tension, similar values in the solutions with and without $\beta$-carotene were obtained $(29.6 \pm 0.2$ and $30.1 \pm 0.1 \mathrm{mN} / \mathrm{m})$, showing that the $\beta$-carotene incorporation does not modify the penetration resistance of the solution $(p \leq 0.05)$. Ramos-Hernández et al. (2018) [18] analyzed the surface tension of HDPAF solutions at different concentrations, obtaining a value of $23.46 \mathrm{mN} / \mathrm{m}$ for a $50 \%$ solution of the polymer, which differs from those obtained in this study. The difference could be associated with the type of surfactant used, but mainly at the concentration of the biopolymer ( $70 \%)$. In contrast, the addition of $\beta$-carotene to the polymer solution caused a significant increase in electrical conductivity from $5.54 \pm 0.01$ to $7.30 \pm 0.03 \mathrm{mS} / \mathrm{cm}$, and this can be attributed to the functional group loads of $\beta$-carotene (Table 1 ).

Table 1. Physicochemical characterization of the $70 \%$ high degree of polymerization agave fructans (HDPAF) polymer solution with and without $\beta$-carotene.

\begin{tabular}{ccc}
\hline Parameter & 70\% HDPAF without $\beta$-Carotene & 70\% HDPAF with $\beta$-Carotene $^{\mathrm{a}}$ \\
\hline Viscosity $^{1}(\mathrm{~Pa} \cdot \mathrm{s})$ & $3.69 \pm 0.05^{\mathrm{a}}$ & $3.36 \pm 0.03^{\mathrm{a}}$ \\
Surface tension $(\mathrm{mN} / \mathrm{m})$ & $30.1 \pm 0.1^{\mathrm{b}}$ & $29.6 \pm 0.2^{\mathrm{b}}$ \\
Electrical conductivity $(\mathrm{mS} / \mathrm{cm})$ & $5.54 \pm 0.01^{\mathrm{c}}$ & $7.30 \pm 0.03^{\mathrm{d}}$ \\
\hline
\end{tabular}

Different letters within the same row indicate significant differences among samples $(\alpha=0.05)$. The average values were obtained from the analysis of three replicas. ${ }^{1}$ Viscosity values were read at a shear rate of $39.8 \mathrm{~s}^{-1}$.

In the electrospinning process, the high concentrations of HDPAF allowed the increase of intermolecular interactions of the polymer with the solvent, and in the same way, the polymer-polymer crosslinking, favoring the stability of the flow [17]. In addition, polymer chain interactions have a close relationship with concentration and viscosity [24]. However, a high viscosity can cause clogging of the injector partially or totally, but it can also affect the morphology of the fibers due to the presence of artifacts in the structures.

\subsection{Micro-Nanofiber Formation Process}

The stabilization of the electrospinning process was achieved with a voltage of $19 \mathrm{kV}, 200 \mu \mathrm{L} / \mathrm{h}$ feed flow of the polymer solution, $20 \mathrm{~cm}$ distance from the injector to the collector with $500 \mathrm{rpm}$ rotation. A concentration of the polymer of $70 \%(w / w)$ was used, which allowed the formation of a network of polymer chains and enough entanglement to electro-stretch the solution, obtaining continuous fibers (Figure 1).

In preliminary studies, the electrospinning process was carried out with a $60 \%$ solution $(w / w)$ of HDPAF concentration. The presence of structures, with artifacts that cannot be considered as spheres or fibers, was observed (Figure 1a). On the contrary, for a concentration of $70 \%$ of HDPAF, it was possible to obtain a homogeneous film on the collector. This is directly related to the increase in concentration, the structure of high-polymerization fructans and the molecular arrangement of the terminal chains and interactions that occur during the electrospinning process.

Despite not finding references in literature about fiber formation with HDPAF, some authors such as Lee et al. (2009) [25]; Kai et al. (2015) [26] reported the use of polysaccharides such as alginate, cellulose, chitosan, starch in the formation of fibers by electrospinning, which could be used as natural encapsulants in the area of medicine. HDPAFs have just been used so far for the production of spherical nanocapsules ([18]), which were obtained using a HDPAF concentration of 30\% through the 
electrospraying process to encapsulate $\beta$-carotene. The possibility of obtaining fibers could increase the application field of agave fructans to medicine or biomaterials.

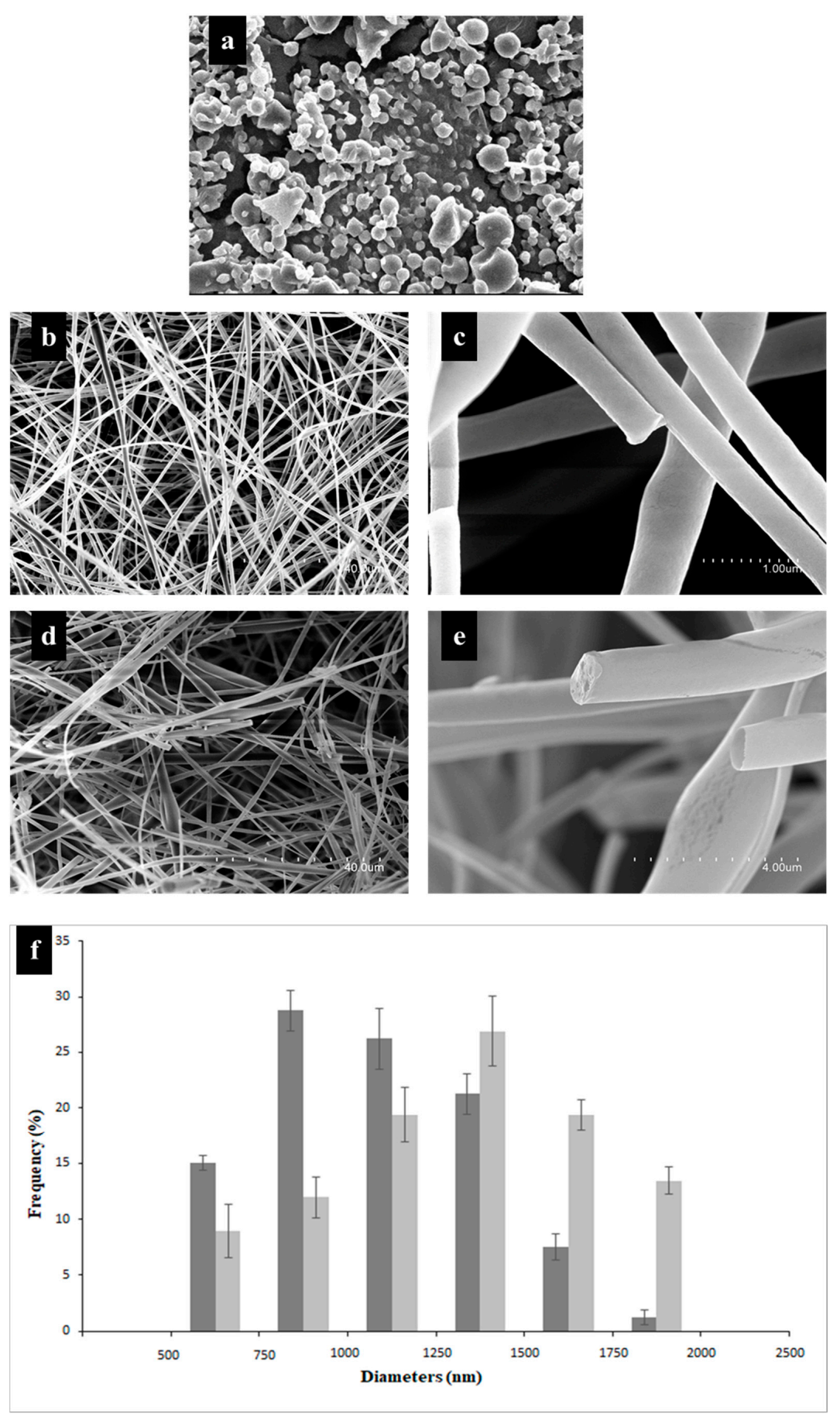

Figure 1. Scanning electron microscopy (SEM) micrographs show structures obtained with (a) $60 \%$ HDPAF, (b,c) fibers obtained with 70\% HDPAF without $\beta$-carotene at different magnification, (d,e) fibers obtained with $70 \%$ HDPAF loaded with $\beta$-carotene at different magnification, (f) distribution of micro-nanofiber diameters obtained with the 70\% HDPAF formulation (घ) without and (घ) with $\beta$-carotene. The average values and standard deviation (SD) were obtained from the analysis of three replicas. 


\subsection{Morphology Analysis}

Fibers obtained with solutions without $\beta$-carotene presented a smooth and continuous surface (Figure 1d) with a larger distribution of diameters, in the range of 750 to $1000 \mathrm{~nm}$ (Figure 1f). Structures obtained with $\beta$-carotene showed smooth, continuous surface fibers, with a slight fragmentation of some structures. This is possibly associated with the applied voltage and its effect on the breaking of the cross-links of the polymer chains. An increase in the diameter size distribution was observed, being in the range between 1250 and $1500 \mathrm{~nm}$. The presence of pores and widenings in some segments was observed, which could be due to the lipophilic nature of $\beta$-carotene that limits cross-linking with the polymer or the relative humidity and vapor pressure of the solvent used. The high hygroscopicity of the HDPAF could also affect the diameter of the fibers. Bak et al. (2016) [27] analyzed the effect of relative humidity $(30 \%$ and $60 \%)$ in the manufacture of collagen nanofibers. These authors reported that the quantity of humidity affects the morphological characteristics of the fibers obtained, and therefore concluded that at lower humidity the diameter of the fibers decreases.

\subsection{Loading and Encapsulation Efficiency (LE and EE)}

The encapsulation efficiency of the $\beta$-carotene inside the ultrathin fibers of HDPAF was $95 \%$. This indicates that almost all the loaded compound was encapsulated in the center of the fibers. This value differs with the encapsulation efficiencies obtained with other polysaccharides, such as chitosan, where an encapsulation efficiency of $\beta$-carotene of $36 \%$ was obtained in the encapsulation by nanomicelles. However, it is similar to the encapsulation efficiency reported for the encapsulation of anthocyanins in xanthan gum in combination with starch $(96 \%)$ by spray drying $[28,29]$. HDPAFs show similarities in their entrapment capacity compared to some proteins. In this sense, López-Rubio and Lagaron (2012) [30] report a 90\% of encapsulation efficiency for the encapsulation of $\beta$-carotene in whey protein. Gomez-Estaca et al. (2012) [31] obtain an encapsulation efficiency between 85 and $90 \%$ in encapsules of curcumin into zein by electrospraying. The branched structure of the HDPAF favors the entrapment of the bioactive compound due to its available functional groups, forming bonds such as hydrogen bonds that stabilize the nucleus and maintain the compound of interest in the fiber. The loading efficiency was of $85 \%$ in the fibers based on thermogravimetric analysis.

\subsection{Thermogravimetric Analysis}

A thermogravimetric analysis was performed to the fibers as well as to each of the materials used to make the fibers, in order to study the thermal stability of the $\beta$-carotene inside the polymeric wall of HDPAF. The $\beta$-carotene displayed an initial decomposition temperature of $138{ }^{\circ} \mathrm{C}$ and a final temperature of $367^{\circ} \mathrm{C}$ (Figure $2 \mathrm{~b}$ ), similar to the temperatures reported by Peinado et al. (2016) [32] when analyzing this powder compound with a maximum peak of decomposition at approximately $120^{\circ} \mathrm{C}$. In addition, there were two important variations in mass, which are related to the breakdown of the basic structure due to thermal energy, generating the formation of volatile organic compounds including 2-methyl-2-hepten-6-yne, 2-methyl-2-hepten-4-yne and $\beta$ cyclocitral.

The thermal stability of the fibers in the absence of $\beta$-carotene (Figure $2 b$ ) was characterized by presenting a first weight loss of $5.0 \%$ at $100{ }^{\circ} \mathrm{C}$, which is associated with the humidity content. The second variation occurred between 167 to $307^{\circ} \mathrm{C}$, attributed to HDPAF (57.91\%), reaching the maximum decomposition temperature at $209^{\circ} \mathrm{C}$. This temperature is similar to that presented by the individually analyzed HDPAFs, which explains that the surfactant used does not modify the thermal properties of the polymer. Espinosa-Andrews and Urias-Silvas (2012) [33] reported decomposition temperatures of 200 to $222^{\circ} \mathrm{C}$ for commercial agave fructans, with a similar thermal behavior to that reported in this study. Regarding the fibers with $\beta$-carotene, the thermogram showed three mass variations (Figure 2b). 
The first corresponds to humidity (4.0\%), the second, between 174 to $232{ }^{\circ} \mathrm{C}$, is attributed to the breakdown of HDPAF according to Figure 2a, the third was in the temperature range of 232 to $288^{\circ} \mathrm{C}$, which was related with the breakdown of $\beta$-carotene, a higher degree of polymerization fructans and surfactant according to Figure $2 \mathrm{~b}$. This can be explained due to the nature of the compounds and their affinity between $\beta$-carotene and HDPAF. Likewise, the fibers with $\beta$-carotene showed a displacement of $90{ }^{\circ} \mathrm{C}$ in the initial decomposition temperature of this compound, demonstrating the thermoprotective effect of HDPAF.
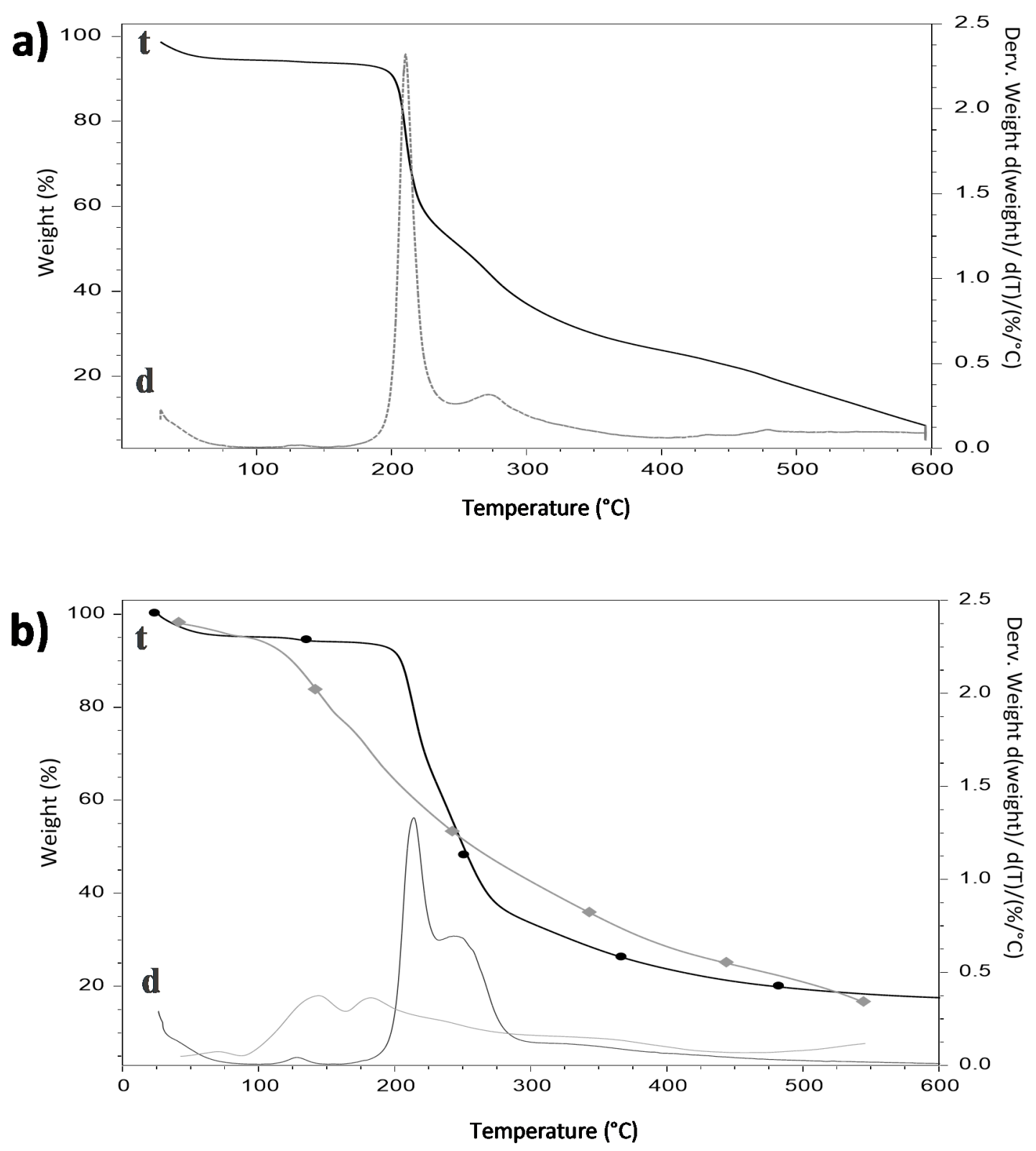

Figure 2. Thermograms of (a) HDPAF and (b) comparative $(\downarrow) \beta$-carotene $(\bullet)$ fibers with $\beta$-carotene. $(t$, indicates thermograms and $d$, the derivatives of the thermograms).

\subsection{Photostability Analysis}

The need to evaluate the protection capacity of polymers used in encapsulation processes arises due to the susceptibility of photosensitive compounds to structural modification, such as $\beta$-carotene. The photostability of the fibers was evaluated under exposure of the fibers to ultraviolet A (UVA) 
light. According to the results, the photooxidation of uncapsulated $\beta$-carotene was presented from the beginning of the exposure, becoming total at $24 \mathrm{~h}$.

On the contrary, when $\beta$-carotene was encapsulated within the fibers, the loss of its relative content was only $21 \%$ until $48 \mathrm{~h}$ (Figure 3). This behavior shows the ability of HDPAFs to reduce the photooxidation process, thus, prolonging the stability of $\beta$-carotene. Ramos-Hernández et al. (2018) [18] prepared capsules with HDPAF using a polymer concentration of $30 \%$ and $0.1 \%$ of $\beta$-carotene, and the results in the oxidation of $\beta$-carotene encapsulated with the electrospraying method showed a loss of $10 \%$ in capsules within $48 \mathrm{~h}$. If the protective effect of both morphologies is compared, it is possible to observe that the fibers show twice the oxidation than the capsules, although the $\beta$-carotene content is 10 times higher in the fibers. The loss of photostability could be attributed to a reduced biopolymer-bioactive ratio, as well as to an effect of morphology, since the fibers have a larger surface exposed to light. For this reason, taking into account the amount of encapsulated $\beta$-carotene and the encapsulation efficiency obtained, the photostabilizing effect of the fiber could be considered very adequate.

In comparison with synthetic polymers, the behavior of the fibers with $\beta$-carotene is similar to that presented with the use of HDPAF. Peinado et al. (2016) [32] report a 20\% loss of the relative content of the bioactive compound when exposed to UVA fibers made with polyethylene oxide (PEO) attributed to the stability of $\beta$-carotene once encapsulated, reflecting the polymer ability to limit oxygen diffusion and reduce exposure to light. On the other hand, de Freitas Zômpero et al. (2015) [34] obtain a 20\% reduction after $6 \mathrm{~h}$ of exposure to UV light in fibers made with polyvinyl alcohol (PVOH) loaded with nanoliposomes, with the aim of analyzing the stability of the $\beta$-carotene. Whereas, the fibers in the present study show a reduction of $7 \%$ in the same period of time, which proves that HDPAFs have the ability to protect photosensitive compounds.

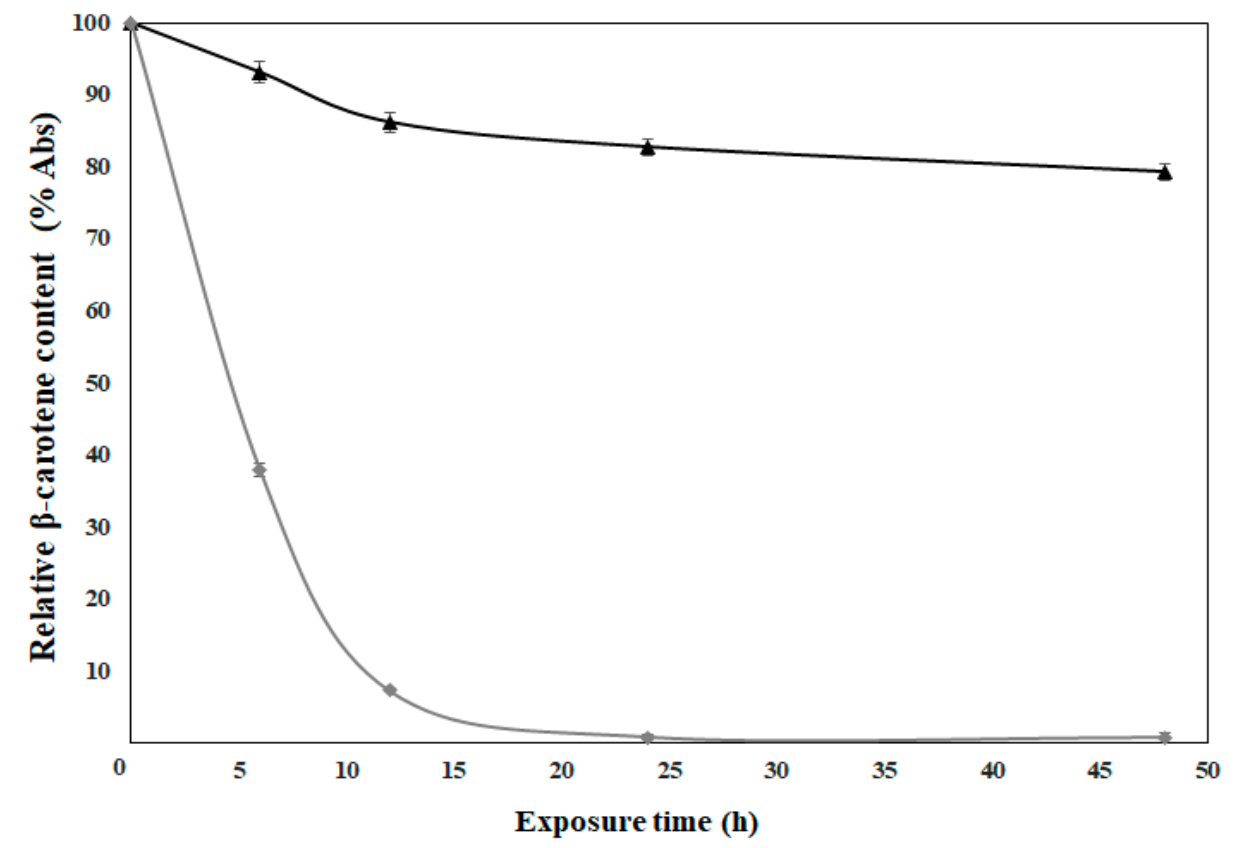

Figure 3. Photostability kinetics of the $\beta$-carotene $(\downarrow)$ and 70\% HDPAF micro-nanofibers loaded with $\beta$-carotene ( $\mathbf{\Lambda})$.

\section{Conclusions}

To the best of our knowledge, this paper reports for the very first time the possibility of generating continuous micro- and nanometric scale fibers from agave fructans of high degree of polymerization in $70 \%(w / w)$ solutions. This document also reports the possibility to encapsulate a bioactive model 
compound, such as $\beta$-carotene inside the fibers, obtaining a high encapsulation efficiency as well as providing stability to both temperature and UVA radiation.

The good results provided by fructans could suppose the expansion of its use and exploitations, since they could be a feasible alternative to replace synthetic polymers in the encapsulation of compounds of high biological value, as well as expanding their use in biomedical and pharmaceutical products. In this spirit, it is of important interest to consider the study of possible complexes with other polymers that help enhance their characteristics and properties, such as its high hygroscopicity, and structures more homogeneous, as well as their incursion into new applications.

Author Contributions: Conceptualization by J.A.R.-S. and J.M.L.; methodology, validation, and formal analysis was carried out by C.N.C.-S., J.A.R.-S., M.C.-S., C.P., and J.M.L.; investigation, resources, data curation, writing - original draft preparation and writing-review and editing was performed by C.N.C.-S., J.A.R.-S., M.C.-S., C.P., and J.M.L.; visualization, supervision, project administration, funding acquisition was carried out by J.A.R.-S. and J.M.L.

Funding: This study was supported by the Consejo Nacional de Ciencia y Tecnoligía (CONACyT, Mexico) for the scholarship granted (Number 702624) to Carla Norma Cruz Salas; CYTED thematic network code 319RT0576 and Spanish Ministry of Science, Innovation and Universities (proyect code RTI2018-097249-B-C21).

Acknowledgments: We thank Rosa Isela Ortiz-Basurto for providing the high degree of polymerization Agave fructans (HDPAF), Jorge Alberto Ramos-Hernandez and Elda Margarita Gonzalez-Cruz for your technical assistance.

Conflicts of Interest: The authors declare no conflict of interest.

\section{References}

1. Apolinário, A.C.; De Lima Damasceno, B.P.G.; De Macêdo Beltrão, N.E.; Pessoa, A.; Converti, A.; Da Silva, J.A. Inulin-Type Fructans: A Review on Different Aspects of Biochemical and Pharmaceutical Technology. Carbohydr. Polym. 2014, 101, 368-378. [CrossRef]

2. Saénz, C.; Tapia, S.; Chávez, J.; Robert, P. Microencapsulation by Spray Drying of Bioactive Compounds from Cactus Pear (Opuntia Ficus-Indica). Food Chem. 2009, 114, 616-622. [CrossRef]

3. Moreno-Vilet, L.; Bostyn, S.; Flores-Montaño, J.L.; Camacho-Ruiz, R.M. Size-Exclusion Chromatography (HPLC-SEC) Technique Optimization by Simplex Method to Estimate Molecular Weight Distribution of Agave Fructans. Food Chem. 2017, 237, 833-840. [CrossRef] [PubMed]

4. Waleckx, E.; Gschaedler, A.; Colonna-Ceccaldi, B.; Monsan, P. Hydrolysis of Fructans from Agave Tequilana Weber Var. Azul during the Cooking Step in a Traditional Tequila Elaboration Process. Food Chem. 2008, 108, 40-48. [CrossRef]

5. García Gamboa, R.; Ortiz Basurto, R.I.; Calderón Santoyo, M.; Bravo Madrigal, J.; Ruiz Álvarez, B.E.; González Avila, M. In Vitro Evaluation of Prebiotic Activity, Pathogen Inhibition and Enzymatic Metabolism of Intestinal Bacteria in the Presence of Fructans Extracted from Agave: A Comparison Based on Polymerization Degree. LWT Food Sci. Technol. 2018, 92, 380-387. [CrossRef]

6. Farías-Cervantes, V.S.; Chávez-Rodríguez, A.; Delgado-Licon, E.; Aguilar, J.; Medrano-Roldan, H.; Andrade-González, I. Effect of Spray Drying of Agave Fructans, Nopal Mucilage and Aloe Vera Juice. J. Food Process. Preserv. 2017, 41, e13027. [CrossRef]

7. Lopez, M.G.; Mancilla-Margalli, N.A.; Mendoza-Diaz, G. Molecular Structures of Fructans from Agave Tequilana Weber Var. Azul. J. Agric. Food Chem. 2003, 51, 7835-7840. [CrossRef]

8. Da Fonseca Contado, E.W.N.; de Rezende Queiroz, E.; Rocha, D.A.; Fraguas, R.M.; Simao, A.A.; Botelho, L.N.S.; de Fatima Abreu, A.; de Abreu, M.A.B.C.M.P. Extraction, Quantification and Degree of Polymerization of Yacon (Smallanthus Sonchifolia) Fructans. Afr. J. Biotechnol. 2015, 14, 1783-1789. [CrossRef]

9. Carranza, C.O.; Fernandez, A.Á.; Bustillo Armendáriz, G.R.; López-Munguía, A. Processing of Fructans and Oligosaccharides from Agave Plants; Elsevier Inc.: Amsterdam, The Netherlands, 2014. [CrossRef]

10. Toriz, G.; Delgado, E.; Zúñiga, V. A Proposed Chemical Structure for Fructans from Blue Agave Plant (Tequilana Weber Var. Azul). Rev. Electrónica Y Tecnológica e-Gnosis 2007, 5, 1.

11. Ortiz-Basurto, R.I.; Rubio-Ibarra, M.E.; Ragazzo-Sanchez, J.A.; Beristain, C.I.; Jiménez-Fernández, M. Microencapsulation of Eugenia Uniflora L. Juice by Spray Drying Using Fructans with Different Degrees of Polymerisation. Carbohydr. Polym. 2017, 175, 603-609. [CrossRef] 
12. Farías Cervantes, V.S.; Delgado Lincon, E.; Solís Soto, A.; Medrano Roldan, H.; Andrade González, I. Effect of Spray Drying Temperature and Agave Fructans Concentration as Carrier Agent on the Quality Properties of Blackberry Powder. Int. J. Food Eng. 2016, 12, 451-459. [CrossRef]

13. Wen, P.; Zong, M.H.; Linhardt, R.J.; Feng, K.; Wu, H. Electrospinning: A Novel Nano-Encapsulation Approach for Bioactive Compounds. Trends Food Sci. Technol. 2017, 70, 56-68. [CrossRef]

14. Anu Bhushani, J.; Anandharamakrishnan, C. Electrospinning and Electrospraying Techniques: Potential Food Based Applications. Trends Food Sci. Technol. 2014, 38, 21-33. [CrossRef]

15. Haider, A.; Haider, S.; Kang, I.K. A Comprehensive Review Summarizing the Effect of Electrospinning Parameters and Potential Applications of Nanofibers in Biomedical and Biotechnology. Arab. J. Chem. 2018, 11, 1165-1188. [CrossRef]

16. Le Corre-Bordes, D.; Hofman, K.; Hall, B. Guide to Electrospinning Denatured Whole Chain Collagen from Hoki Fish Using Benign Solvents. Int. J. Biol. Macromol. 2018, 112, 1289-1299. [CrossRef] [PubMed]

17. Ghorani, B.; Tucker, N. Fundamentals of Electrospinning as a Novel Delivery Vehicle for Bioactive Compounds in Food Nanotechnology. Food Hydrocoll. 2015, 51, 227-240. [CrossRef]

18. Ramos-Hernández, J.; Ragazzo-Sánchez, J.; Calderón-Santoyo, M.; Ortiz-Basurto, R.; Prieto, C.; Lagaron, J. Use of Electrosprayed Agave Fructans as Nanoencapsulating Hydrocolloids for Bioactives. Nanomaterials 2018, 8, 868. [CrossRef]

19. Fernandez, A.; Torres-Giner, S.; Lagaron, J.M. Novel Route to Stabilization of Bioactive Antioxidants by Encapsulation in Electrospun Fibers of Zein Prolamine. Food Hydrocoll. 2009, 23, 1427-1432. [CrossRef]

20. Ozkan, G.; Franco, P.; De Marco, I.; Xiao, J.; Capanoglu, E. A Review of Microencapsulation Methods for Food Antioxidants: Principles, Advantages, Drawbacks and Applications. Food Chem. 2019, 272, 494-506. [CrossRef]

21. Fu, D.; Deng, S.; McClements, D.J.; Zhou, L.; Zou, L.; Yi, J.; Liu, C.; Liu, W. Encapsulation of $\beta$-Carotene in Wheat Gluten Nanoparticle-Xanthan Gum-Stabilized Pickering Emulsions: Enhancement of Carotenoid Stability and Bioaccessibility. Food Hydrocoll. 2019, 89, 80-89. [CrossRef]

22. González-Reza, R.M.; Quintanar-Guerrero, D.; Flores-Minutti, J.J.; Gutiérrez-Cortez, E.; Zambrano-Zaragoza, M.L. Nanocapsules of $\beta$-Carotene: Thermal Degradation Kinetics in a Scraped Surface Heat Exchanger (SSHE). LWT Food Sci. Technol. 2015, 60, 124-130. [CrossRef]

23. Kutzli, I.; Gibis, M.; Baier, S.K.; Weiss, J. Electrospinning of Whey and Soy Protein Mixed with Maltodextrin-Influence of Protein Type and Ratio on the Production and Morphology of Fibers. Food Hydrocoll. 2019, 93, 206-214. [CrossRef]

24. Hulsey, S.; Absar, S.; Choi, H. Comparative Study of Polymer Dissolution Techniques for Electrospinning. Procedia Manuf. 2017, 10, 652-661. [CrossRef]

25. Lee, K.Y.; Jeong, L.; Kang, Y.O.; Lee, S.J.; Park, W.H. Electrospinning of Polysaccharides for Regenerative Medicine. Adv. Drug Deliv. Rev. 2009, 61, 1020-1032. [CrossRef] [PubMed]

26. Kai, D.; Liow, S.S.; Loh, X.J. Biodegradable Polymers for Electrospinning: Towards Biomedical Applications. Mater. Sci. Eng. C 2015, 45, 659-670. [CrossRef] [PubMed]

27. Bak, S.Y.; Yoon, G.J.; Lee, S.W.; Kim, H.W. Effect of Humidity and Benign Solvent Composition on Electrospinning of Collagen Nanofibrous Sheets. Mater. Lett. 2016, 181, 136-139. [CrossRef]

28. Cai, X.; Du, X.; Cui, D.; Wang, X.; Yang, Z.; Zhu, G. Improvement of Stability of Blueberry Anthocyanins by Carboxymethyl Starch/Xanthan Gum Combinations Microencapsulation. Food Hydrocoll. 2019, 91, 238-245. [CrossRef]

29. Ge, W.; Li, D.; Chen, M.; Wang, X.; Liu, S.; Sun, R. Characterization and Antioxidant Activity of $\beta$-Carotene Loaded Chitosan-Graft-Poly (Lactide) Nanomicelles. Carbohydr. Polym. 2015, 117, 169-176. [CrossRef]

30. López-Rubio, A.; Lagaron, J.M. Whey Protein Capsules Obtained through Electrospraying for the Encapsulation of Bioactives. Innov. Food Sci. Emerg. Technol. 2012, 13, 200-206. [CrossRef]

31. Gomez-Estaca, J.; Balaguer, M.P.; Gavara, R.; Hernandez-Munoz, P. Formation of Zein Nanoparticles by Electrohydrodynamic Atomization: Effect of the Main Processing Variables and Suitability for Encapsulating the Food Coloring and Active Ingredient Curcumin. Food Hydrocoll. 2012, 28, 82-91. [CrossRef]

32. Peinado, I.; Mason, M.; Romano, A.; Biasioli, F.; Scampicchio, M. Stability of $\beta$-Carotene in Polyethylene Oxide Electrospun Nanofibers. Appl. Surf. Sci. 2016, 370, 111-116. [CrossRef] 
33. Espinosa-Andrews, H.; Urias-Silvas, J.E. Thermal Properties of Agave Fructans (Agave Tequilana Weber Var. Azul). Carbohydr. Polym. 2012, 87, 2671-2676. [CrossRef]

34. De Freitas Zômpero, R.H.; López-Rubio, A.; de Pinho, S.C.; Lagaron, J.M.; de la Torre, L.G. Hybrid Encapsulation Structures Based on $\beta$-Carotene-Loaded Nanoliposomes within Electrospun Fibers. Colloids Surf. B Biointerfaces 2015, 134, 475-482. [CrossRef] [PubMed] 